\title{
Arahan Pengembangan Kawasan Wisata Pantai Karanggongso dan Pantai Prigi di Kabupaten Trenggalek
}

\author{
Astarina Cleosa Damayanti, Arwi Yudhi Koswara \\ Departemen Perencanaan Wilayah dan Kota, Fakultas Teknik Sipil dan Perencanaan, Institut \\ Teknologi Sepuluh Nopember \\ e-mail: arwiyudhi@gmail.com
}

\begin{abstract}
Abstrak-Kabupaten Trenggalek merupakan Kabupaten pada pesisir selatan yang memiliki potensi wisata pantai yang besar. Pantai yang berkembang adalah pantai Karanggongso dan pantai Prigi. Kedua pantai tersebut memiliki karakteristik yang berbeda yang mengakibatkan terjadinya perbedaan jumlah kunjungan yang signifikan. Selama ini pengembangan kepariwisataan kurang adanya keterpaduan pembangunan komponen daya tarik wisata.. Oleh karena itu tujuan dari penelitian ini adalah arahan pengembangan kawasan wisata Pantai Karanggongso dan Pantai Prigi di Kabupaten Trenggalek. Penelitian ini dilakukan pada 2 pantai yaitu pantai Karanggongso dan pantai Prigi. Analisis yang digunakan adalah analisis deskriptif, Delphi dan triangulasi. Hasil dari penelitian ini berupa arahan pengembangan kawasan wisata pantai Karanggongso dan pantai Prigi, yaitu pada ODTW di pantai Karanggongso diharapkan mempertahankan atraksi wisata yang ada, sedangkan pantai Prigi harus menambahkan atraksi wisata dan mempertahankan Larung Sambonyo. Pada aksesibilitas diarahkan untuk pelebaran jalan dan memperbaiki kondisi jalan. Perbaikan dan penambahan fasilitas dan infrastruktur. Aspek kelembagaan dan partisipasi masyarakat juga diperlukan demi perkembangan kawasan wisata pantai. Untuk menjaga keindahan pantai diarahkan untuk selalu menjaga kondisi lingkungan baik didarat maupun bawah laut serta pentingnya promosi wisata untuk lebih mengenalkan kawasan wisata pantai Karanggongso dan pantai Prigi.
\end{abstract}

Kata Kunci- pengembangan pariwisata, wisata pantai.

\section{PENDAHULUAN}

$\mathrm{S}_{\mathrm{k}}^{\mathrm{A}}$ ALAH satu tantangan pengembangan pariwisata adalah kondisi pengembangan pariwisata yang masih bertumpu pada daerah tujuan wisata utama tertentu saja. Pemusatan kegiatan wisata pada destinasi utama menyebabkan potensi wisata yang lainnya tidak dapat mengembangkan potensi yang dimiliki sebagaimana mestinya [1]

Menurut RTRW Kabupaten Trenggalek Tahun 2011-2031 Kabupaten Trenggalek merupakan salah satu Kabupaten di Jawa Timur yang memiliki sektor pariwisata bahari yang beragam. Kabupaten Trenggalek memiliki panjang pantai sekitar $71.117 \mathrm{~km}$ serta memiliki 57 pulau. Beberapa yang potensial adalah kawasan wisata pantai di Kecamatan Watulimo yang terdiri dari Pantai Karanggongso dan Pantai Prigi. Dari Kecamatan Watulimo ini, PAD dari sektor pariwisata yang masuk ke daerah (kasda) bisa mencapai 70 persen dari total pendapatan masuk dari sektor yang sama [2]

Namun dilihat dari data Dinas Pariwisata, Pemuda dan Olahraga Kabupaten Trenggalek, jumlah wisatawan yang berkunjung di Pantai Karanggongso dan pantai Prigi pada tahun 2012 sampai 2016 terjadi perbedaan jumlah kunjungan yang sangat signifikan. Pantai Karanggangso terjadi kenaikan disetiap tahunnnya, jika pantai Prigi terjadi ketidak stabilan pengunjung. Berikut adalah jumlah kunjungan pada pantai Karanggongso pada tahun 2012-2016 adalah 263.584, 288.165, 337.180, 358.596, 393.903. sedangkan pamtai Prigi 81.567, 88.374, 82.211, 90.251, 77.256 pengunjung.[3]

Kawasan wisata pantai Karanggongso dan pantai Prigi merupakan wisata pantai selatan yang dapat dikembangkan karena memiliki jumlah pengunjung yang cukup banyak disetiap tahunnya. Kawasan wisata ini cukup potensial untuk dikembangkan menjadi kegiatan pariwisata yang lebih baik dan menjadi objek wisata yang mampu menarik minat wisatawan untuk berkunjung. Sehingga dapat meningkatkan jumlah pengujung di kawasan wisata pantai Karanggongso dan pantai Prigi. Kemudian dengan adanya kegiatan di kawasan wisata tersebut dapat menggerakkan perekonomian masyarakat lokal di Kecamatan Watulimo serta menambah pendapatan asli daerah. Secara teoritis perkembangan suatu kawasan wisata dapat dipengaruhi oleh banyak faktor, sehingga diperlukan kajian pengembangan kawasan wisata pantai Karanggongso dan pantai Prigi.

\section{METODE}

Jenis penelitian dalam penelitian ini adalah deskriptif kualitatif dengan pendekatan penelitian yang digunakan adalah pendekatan rasionalistik.[4] Pada penelitian ini terdapat 22 variabel. Variabel penelitian tersebut digunakan untuk sasaran 1 yaitu analisis karakteristik komponen pariwisata di kawasan wisata Pantai Karanggongso dan Pantai Prigi di Kabupaten Trenggalek dan sasaran 2 yaitu menentukan faktor-faktor penentu pengembangan kawasan wisata Pantai Karanggongso dan Pantai Prigi di Kabupaten Trenggalek. Tahapan yang dilalui untuk menghasilkan arahan pengembangan kawasan wisata pantai Karanggongso dan pantai Prigi di Kabupaten Trenggalek ini terbagi menjadi 3 (tiga), yaitu: (1) menganalisis karakteristik komponen pariwisata; (2) menentukan faktor- 
faktor penentu pengembangan kawasan wisata; (3) memberikan arahan pengembangan kawasan wisata pantai Karanggonso dan pantai Prigi. Metode analisis yang digunakan pada tahap pertama adalah analisis deskriptif kualitatif berdasarkan hasil observasi dan juga survey sekunder. Selanjutnya pada tahap kedua metode analisis yang digunakan adalah analisis Delphi dengan menyebar kuisoner ke beberapa stakeholders. Pada tahap terakhir menggunakan analisis triangulasi dengan cara mengkomparasikan antara kondisi eksisting, peraturan yang ada serta penelitian sebelumnya .

\section{HASIL DAN PEMBAHASAN}

Wilayah studi dalam penelitian ini adalah pantai Karanggongso dan pantai Prigi di Kecamatan Watulimo, Kabupaten Trenggalek. Dengan batas wilayah sebagai berikut:

- Sebelah utara : Desa Prigi, Desa Watulimo, Desa Margomulyo dan KabupatenTulungagung

- Sebelah timur : Kec Besuki, Kab Tulungagung

- Sebelah barat : Kec Munjungan

- Sebelah selatan : Samudera Hindia

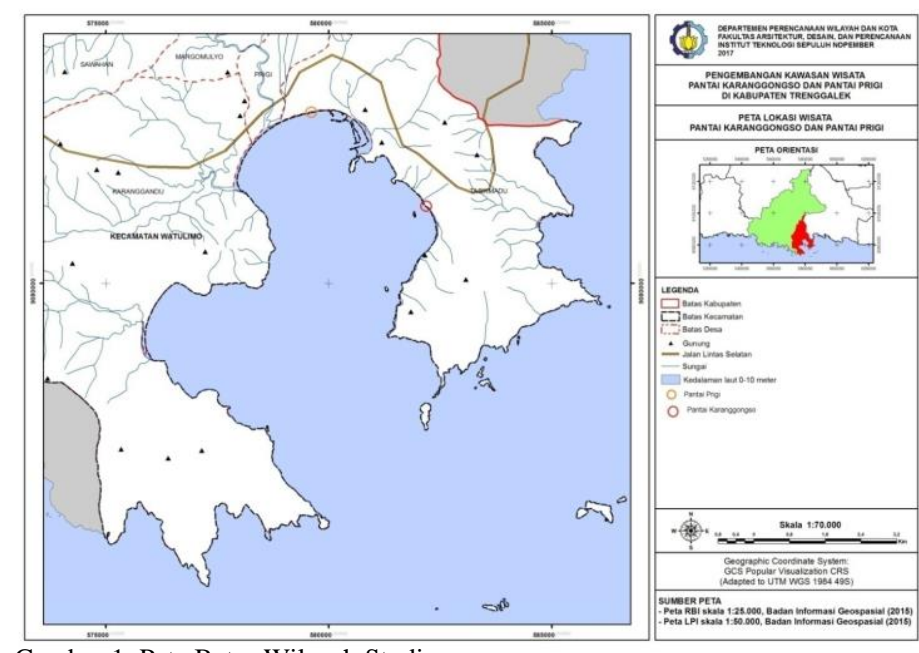

Gambar 1. Peta Batas Wilayah Studi.

A. Analisis karakteristik komponen pariwisata di kawasan wisata Pantai Karanggongso dan Pantai Prigi

Untuk merumuskan arahan pengembangan kawasan wisata Pantai Karanggongso dan Pantai Prigi di Kabupaten Trenggalek melalui beberapa sasaran, yang pertama adalah menganalisis karakteristik komponen pariwisata dengan menggunakan analisis deskriptif, komponen pariwisata tersebut dihasilkan dari sintesa tinjauan pustaka. Antara pantai karanggongso dan pantai prigi memiliki perbedaan pada jenis atraksi yang ditawarkan. Pada pantai karanggongso atraksi yang ditawarkan berupa naik perahu mengelilingi pantai, berenang, snorkeling, watersport, serta singgah dipulau seberang. Namun atraksi yang ditawarkan pantai prigi hanya berupa keindahan pulau-pulau kecil dan berenang dibibir pantai.

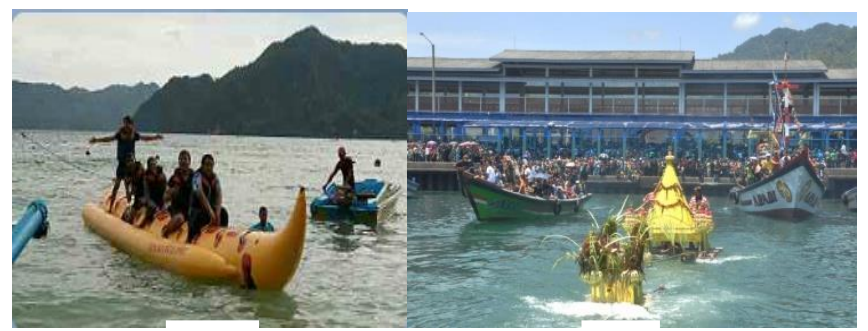

A

B

Gambar A. Atraksi wisata di pantai Karanggongso, B. Upacara larung sambonyo budaya khas pantai Prigi.

Sumber : Survey Primer, 2017.

Aksesibilitas menuju kawasan wisata pantai. Jalan yang dilalui sebagian besar dalam kondisi baik, namun saat memasuki Kecamatan Watulimo kondisi jalan sedikit sempit untuk beberapa kilometer dan dalam kondisi sedikit rusak namun sudah mulai diperbaiki dan angkutan yang tersedia merupakan salah satu alat transportasi yang memudahkan pengunjung untuk dapat mencapai kawasan wisata Pantai Karanggongso dan Pantai Prigi. Namun mini bus ini hanya sampai di terminal watulimo.

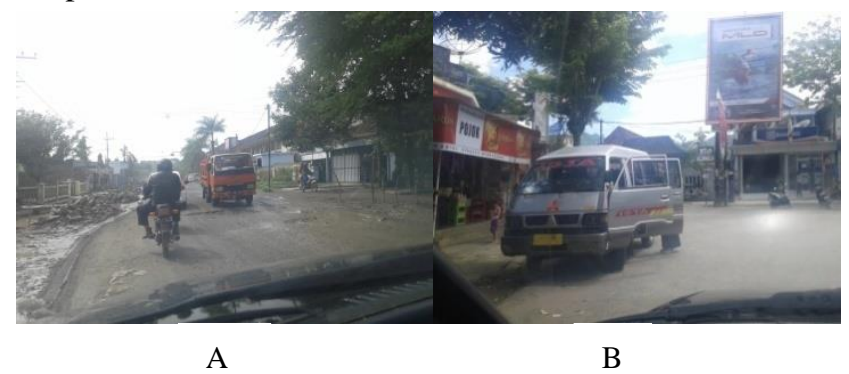

Gambar A. Kondisi jalan Kabupaten Trenggalek menuju kawasan wisata pantai, B. Angkutan umum menuju Kecamatan Watulimo. Sumber : Survey Primer, 2017.

Pantai Karanggongso dan pantai Prigi memiliki fasilitas penginapan, tempat makan, toko souvenir, tempat parkir, fasilitas pelayanan kesehatan, fasilitas keamanan, kantor pelayanan informasi dan fasilitas peribadatan. Namun tempat makan yang ada belum tertata dengan baik masih berupa bangunan non permanen. Tempat parkir saat weekend atau hari libur kurang mendukung karena menyita setengah jalan raya yang mengakibatkan jalan semakin sempit dan menjadi macet. Kawasan wisata ini tersedia air bersih dari PDAM, jaringan listrik. Walaupun jaringan lampu pada kawasan wisata pantai Karanggongso dan pantai Prigi belum terlayani dengan baik dan juga air yang belum mengalir dengan lancar, jaringan telekomunikasi tersedia walaupun belum maksimal.

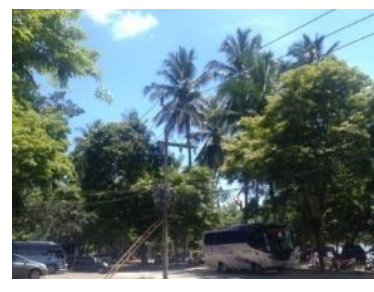

A

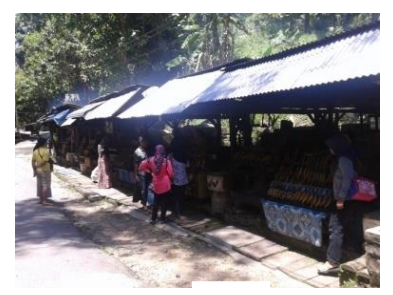

B
Gambar A. Jaringan listrik di kawasan wisata pantai, B. Fasilitas warung makan di kawasan wisata pantai.

Sumber : Survey Primer, 2017.

Kelembagaan yang dimaksud disini adalah kebijakan pengembangan wisata dan koordinasi antar stakeholders. 
Pantai Karanggongso dan pantai Prigi belum memiliki RIPPDA yang berlaku dan koordinasi antar stakeholders juga belum terjalin dengan baik.

Kondisi ekosistem sekitarnya masih menunjukkan kealamiannya, seperti kondisi tumbuhan dihutan sekitarnya yang masih hijau dan kondisi ekosistem laut yang belum tercemar.

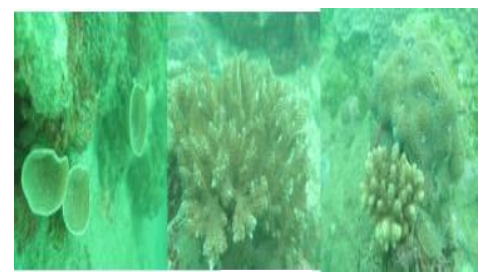

A

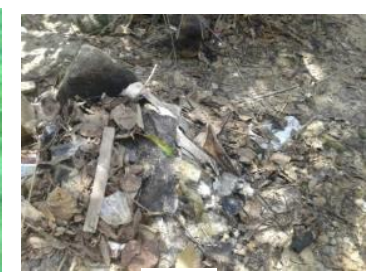

B

Gambar A. Kondisı ekosıstem bawah laut, B. Kondisi lingkungan sekitar. Sumber : Survey Primer, 2017.

Pantai Karanggongso dan pantai Prigi memiliki Lembaga Masyarakat Desa Hutan, komunitas sadar sampah, Kelompok sadar wisata,paguyuban pedagang. Namun status keberadaan kelompok sadar wisata (POKDARWIS) masih belum jelas.

Promosi melalui media sosial berupa website, media cetak berupa informasi parawisata dan budaya. Diadakannya Prigi Festival dan Festival Pantai Selatan sebagai ajang promosi. Atraksi Larung Sambonyo juga sebagai salah satu atraksi yang khas untuk mempromosikan Pantai Prigi. Banyak juga papan petunjuk jalan untuk menuju kawasan wisata pantai. Namun perlu ditambah lagi agar wisatawan dapat lebih tertarik untuk berkunjung ke Pantai Karanggongso maupun Prigi.

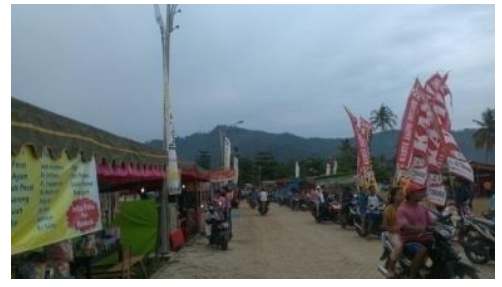

A

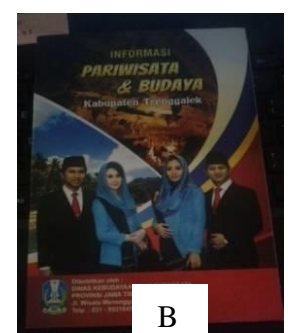

Gambar A. Promosi berupa kegiatan Prigi Fest, B. Promosi berupa informasi wisata media cetak.

Sumber : Survey Primer, 2017

\section{B. Menentukan faktor-faktor penentu pengembangan}

kawasan wisata Pantai Karanggongso dan Pantai Prigi

Kedua adalah menentukan faktor-faktor penentu pengembangan kawasan wisata menggunakan analisis Delphi dengan menyebar kuisoner ke beberapa stakeholders berdasarkan analisis stakeholders maka didapat 7 stakeholders kunci baik dari pihak pemerintah, swasta maupun masyarakat. Dari analisis Delphi dihasilkan 7 indikator dan 22 variabel, yaitu Obyek Daya Tarik Wisata dengan variabel sumber daya di kawasan wisata pantai karanggongso dan prigi, jenis atraksi wisata (what to do/what to see/ what to buy) dan kegiatan kekhasan kawasan wisata pantai karanggongso dan prigi. Aksesibilitas dengan variabel sarana transportasi menuju obyek wisata kondisi jalan menuju obyek wisata (baik/buruk). Fasilitas dengan variabel Fasilitas penginapan, fasilitas warung makan/restoran, toko souvenir, tempat parkir, fasilitas pelayanan kesehatan, fasilitas keamanan, kantor pelayanan informasi, fasilitas peribadatan. Infrastruktur dengan variabel jaringan air bersih, jaringan listrik, jaringan telekomunikasi, sistem persampahan, sistem drainase. Kelembagaan dengan variabel kebijakan pengembangan wisata, koordinasi antar stakeholder. Kondisi lingkungan dengan variabel kebersihan lingkungan dan kondisi ekosistem. Partisipasi masyarakat dengan variabel partisipasi masyarakat dalam pengembangan wisata. Dari variabel tersebut terdapat 2 variabel yang tidak disetujui oleh 2 stakeholders yaitu, variabel ketersediaan sarana transportasi, stakeholder dari masyarakat menganggap bahwa variabel tersebut tidak penting karena masih banyak pengunjung yang memilih menggunakan kendaraan pribadi. Kemudian variabel ketersediaan sistem persampahan tidak disetujui oleh stakeholder dari Bappeda Kabupaten Trenggalek karena di kawasan tersebut tidak ada sistem persampahan, dan dengan tidak adanya sistem persampahan masih bisa menarik minat pengunjung. Setelah dilakukan iterasi berikutnya hasilnya consensus, kedua stakeholders setuju bahwa variabel tersebut berpengaruh terhadap pengembangan wisata.

\section{Merumuskan arahan pengembangan kawasan wisata Pantai Karanggongso dan Pantai Prigi}

Dalam sasran arahan pengembangan kawasan wisata pantai Karanggongso dan pantai Prigi menggunakan analisis triangulasi dengan mengkomparasikan antara karakteistik komponen pariwisata, kebijakan yang ada dan penelitian sebalumnya maka arahan pengembangan kawasan wisata pantai Karanggongso dan pantai Prigi adalah pada ODTW di pantai Karanggongso diharapkan mempertahankan atraksi wisata yang ada, sedangkan pantai Prigi harus menambahkan atraksi wisata yang berbeda dengan pantai Karanggongso agar tidak terjadi persaingan dan mempertahankan Larung Sambonyo sebagai budaya khas di pantai Prigi. Pada aksesibilitas diarahkan untuk pelebaran jalan, memperbaiki kondisi jalan, menambah rute angkutan umum baik di kawasan wisata pantai Karanggongso maupun pantai Prigi. Perbaikan dan penambahan fasilitas dan infrastruktur di pantai Karanggongso dan pantai Prigi juga diperlukan dalam pengembangan pariwisata. Aspek kelembagaan dan partisipasi masyarakat juga diperlukan demi mendukung perkembangan kawasan wisata pantai Karanggongso dan pantai Prigi, lebih memperjelas lagi status POKDARWIS baik di pantai Karanggongso maupun pantai Prigi serta diharpakan segera menyelesaikan RIPDA dan atau peraturan-peraturan lain mengenai kepariwisataan. Untuk menjaga keindahan pantai diarahkan untuk selalu menjaga kondisi lingkungan baik didarat maupun bawah laut serta pentingnya promosi wisata untuk lebih mengenalkan kawasan wisata baik di media cetak maupun elektronik pada pantai Karanggongso dan khususnya pantai Prigi.

\section{KESIMPULAN DAN SARAN}

Dari hasil penelitian ini dapat diketahui bahwa komponen pariwisata yang sudah disepakati merupakan jendela agar mendapatkan arahan pengembangan kawasan wisata pantai Karanggongso dan pantai Prigi. Hal tersebut diperlukan untuk menyelesaikan masalah terkait kurang berkembangnya 
kawasan wisata pantai Karanggongso dan pantai Prigi sehingga dibutuhkan suatu arahan pengembangan yang tepat untuk menyelesaikan permasalahan tersebut. Kesimpulan dari penelitian ini adalah sebagai berikut :

1. ODTW di pantai Karanggongso diharapkan mempertahankan atraksi wisata yang ada, sedangkan pantai Prigi harus menambahkan atraksi wisata yang berbeda dengan pantai Karanggongso agar tidak terjadi persaingan dan mempertahankan Larung Sambonyo

2. Aksesibilitas diarahkan untuk pelebaran jalan dan memperbaiki kondisi jalan.

3. Perbaikan dan penambahan fasilitas dan infrastruktur juga diperlukan dalam pengembangan pariwisata.

4. Aspek kelembagaan dan partisipasi masyarakat juga diperlukan demi perkembangan kawasan wisata pantai.

Saran yang dapat diberikan adalah pada penelitian yang akan datang sebaiknya lebih fokus pada komponen pariwisata yang memang kurang berkembang pada kedua pantai tersebut. Harapannya penelitian ini dapat digunakan pemerintah sebagai acuan pengembangan kawasan wisata pantai Karanggongso dan pantai Prigi.

\section{DAFTAR PUSTAKA}

[1] D. . Prasiasa, Destinasi Pariwisata berbasis Masyarakat. Jakarta: Salemba Humanika, 2010.

[2] S. Fadillah, "Studi:Pengembangan Kawasan Wisata Bahari Kecamatan Watulimo, Kabupaten Trenggalek," ITS, 2015.

[3] Dinas Pariwisata Kabupaten Trenggalek, Potensi Pariwisata tahun 2016. .

[4] E. Umilia, "Pengembangan Air Terjun Coban Pelangi Desa Wisata Gubugklakah Kabupaten Malang Berdasarkan Potensi Ekonomi dan Sosial Masyarakat," Institut Teknologi Sepuluh Nopember, 2017. 